ISSN 0103-8478

\title{
Raios gama na sobrevivência de plantas de maracujazeiro amarelo inoculadas com Fusarium oxysporum $f$ sp. Passiflorae
}

\author{
Gamma rays on the survival of yellow passion fruit inoculated with \\ Fusarium oxysporum $f$ sp. passiflorae
}

\author{
Patrícia Silva Flores ${ }^{I}$ Claudio Horst Bruckner ${ }^{I I}$
}

\section{RESUMO}

A murcha de Fusarium ou fusariose ocorre em diversas regiões produtoras de maracujá amarelo e tem ocasionado grandes danos devido à morte das plantas. A mutagênese associada à seleção in vitro utilizando fitotoxinas possibilita a aplicação de uma pressão de seleção sobre um grande número de propágulos e, assim, pode direcionar a seleção dos mutantes específicos. Neste trabalho, foi analisado o efeito de raios gama sobre a sobrevivência de plantas de maracujazeiro amarelo inoculados com F. oxysporum f. sp. passiflorae. Brotações foliares provenientes de segmentos caulinares de $\boldsymbol{P}$. edulis irradiados a 20Gy foram submetidas a dois ciclos de seleção em meio de cultura suplementado com o filtrado da cultura fúngica (40\% e $50 \%$ de filtrado). As plantas selecionadas foram inoculadas com a suspensão de conídio em casa de vegetação e após, transferidas para o campo em local com histórico da doença. Ao final da etapa de seleção in vitro, sobreviveram $17,05 \%$ das plantas irradiadas e nenhuma planta do tratamento testemunha. A inoculação com a suspensão de conídio não resultou em diferenças significativas na sobrevivência das plantas irradiadas e não irradiadas. No entanto, em condições de campo, foi confirmado o efeito da radiação no aumento da sobrevivência das plantas, sendo verificada a sobrevivência de $77,78 \%$ das plantas irradiadas e a morte de todas as plantas do tratamento testemunha.

Palavras-chave: indução de mutações, murcha de Fusarium, cultura de tecidos, $\boldsymbol{P}$. edulis $\boldsymbol{f}$. flavicarpa.

\section{ABSTRACT}

The Fusarium vascular wilt occurs in several passion fruit producing regions and it has been caused hight plant mortality. Mutagenesis associated with in vitro selection using phytotoxins enables the application of a strong selection pressure on a large number of propagules and driving the selection of specific mutants. In this research, it was investigated the effect of gamma rays on the survival of yellow passion fruit plants inoculated with $\mathbf{F}$. oxysporum $\boldsymbol{f}$. sp. passiflorae. Shoots from stem segments of $\boldsymbol{P}$. edulis irradiated at 20Gy were subjected to two cycles of selection in culture medium supplemented with a fungal culture filtrate (40\% and $50 \%$ of filtrate). The selected plants were inoculated with conidia suspension in greenhouse and then transferred to field with a serious incidence of Fusarium wilt. At the end of the in vitro selection stage no control plants and $17.05 \%$ of irradiated plants survived. The suspension conidia inoculation resulted in no significant differences in survival for irradiated and non-irradiated plants. However, under field conditions radiation positively affect the plant survival. Of the irradiated plants $77.78 \%$ survived and all control plants died.

Key words: mutation induction, Fusarium wilt, tissue culture, $\boldsymbol{P}$. edulis $f$. flavicarpa.

\section{INTRODUÇÃO}

Apesar de o Brasil se destacar na produção mundial de maracujá-amarelo, a cultura ainda apresenta característica itinerante, principalmente devido ao elevado número de doenças que ocorrem nas regiões produtoras, associado à falta de variedades resistentes (MELETTI et al., 2011). A murcha de Fusarium ou fusariose é uma das principais doenças da cultura e tem ocasionado grandes danos, devido à morte das plantas e redução da vida útil dos pomares (SILVA et al., 2011).

Os métodos de controle da doença têm se baseado na utilização de espécies silvestres resistentes para obtenção de híbridos selecionados em área com histórico da doença ou como porta-enxertos para o

IEmpresa Brasileira de Pesquisa Agropecuária (Embrapa), BR 364, 69900-056, CP 321, Rio Branco, AC, Brasil. E-mail: patricia.flores@embrapa.br. Autor para correspondência.

IIDepartamento de Fitotecnia, Universidade Federal de Viçosa (UFV), Viçosa, MG, Brasil. 
maracujazeiro-amarelo, uma vez que o controle químico não é eficiente (MELETTI et al., 2011). Entretanto, a maioria dos híbridos interespecíficos apresenta problemas no desenvolvimento e infertilidade e a enxertia tem sido uma opção pouco atrativa aos produtores por demandar maior trabalho e tempo entre a semeadura e o plantio no campo, além de resultar em plantas de menor vigor (MELETTI et al., 2005, CAVICHIOLI et al., 2011; NOGUEIRA FILHO et al., 2011).

A indução de mutações associada à cultura de tecidos tem sido utilizada para aumentar a frequência de plantas resistentes a doenças causadas por Fusarium em culturas como: ervilha (SHARMA et al., 2010); melão (KANTOGLU et al., 2010); banana (CHEN et al., 2013; JAIN, 2010); e cana de açúcar (MAHLANZA et al., 2013). A associação dessas técnicas é vantajosa em diferentes fases do processo. Durante a etapa de indução das mutações, a cultura de tecidos possibilita o tratamento de um grande número de propágulos com os agentes mutagênicos, aumentando a possibilidade de se obter o mutante com a característica de interesse. Essa condição é essencial para a indução de mutações, uma vez que se trata de um evento aleatório e o resultado é imprevisível (PIRI et al., 2011; SNYMAN et al., 2011). Esta imprevisibilidade é superada durante a fase de seleção através da suplementação do meio de cultura com agentes seletivos (fitotoxinas, sais, dentre outros), os quais favorecem a identificação do mutante com a característica desejada.

Apesar de a seleção in vitro ser realizada sob elevada pressão de seleção e sem a interferência de fatores que afetam a infecção e a expressão do sintoma, como ocorre durante as avaliações a campo (MOHAN JAIN, 2002; SILVA et al., 2011), testes em condições in vivo são fundamentais para verificar a estabilidade da resistência e outras variações positivas ou negativas (MODGIL et al., 2012; MAHLANZA et al., 2013). A técnica de seleção in vitro de variantes genéticos já foi de validade para várias culturas, no entanto, não foram encontrados na literatura trabalhos que tenham testado esta estratégia para o maracujazeiro amarelo. Nesse sentido, este trabalho teve como objetivo avaliar a sobrevivência de plantas de maracujazeiro amarelo irradiadas e não irradiadas, à inoculação com $F$. oxysporum $f$. sp. passiflorae realizada em diferentes ciclos de seleção.

\section{MATERIAL E MÉTODOS}

O material vegetal utilizado foi obtido da germinação in vitro de sementes de híbridos do Programa de Melhoramento Genético de Maracujazeiro da Universidade Federal de Viçosa (UFV), localizados em plantios na área experimental do Setor de Fruticultura da UFV, em Viçosa, Minas Gerais. Cerca de 2.000 explantes de segmentos caulinares das plântulas obtidas foram tratados com 20Gy de raios $\gamma$ produzidos por fonte de ${ }^{60} \mathrm{Co}$ $\left(0,709\right.$ a $\left.0,711 \mathrm{kGy} \mathrm{h}^{-1}\right)$, provenientes de irradiador do tipo Gamma Cell do Centro de Energia Nuclear na Agricultura (CENA) da Universidade de São Paulo, localizado em Piracicaba, São Paulo. A dose de radiação foi estabelecida a partir de estudos prévios. $\mathrm{O}$ isolado de $\boldsymbol{F}$. oxysporum $\boldsymbol{f}$. sp. passiflorae utilizado foi fornecido pela Embrapa - Mandioca e Fruticultura, localizada em Cruz das Almas, BA. O isolado foi preservado em papel filtro e depositado na micoteca da Clínica de Doenças de Plantas do Departamento de Fitopatologia da UFV. Para a obtenção dos explantes de segmentos caulinares, plantas provenientes da germinação de sementes de maracujazeiro em meio MURASHIGE \& SKOOG (1962) (MS) foram segmentadas em porções de $2 \mathrm{~cm}$ de caule contendo uma gema axilar. Os explantes foram transferidos para placas de Petri contendo $30 \mathrm{~mL}$ de meio MS, contendo metade da concentração dos sais. Após as irradiações, os explantes foram transferidos para tubos de ensaio em que havia $10 \mathrm{~mL}$ de meio de cultura MS suplementado com $1 \mathrm{mg} \mathrm{L}^{-1}$ de BAP. O material foi incubado por 120 dias em sala de crescimento com fotoperíodo de 16 horas e densidade de fluxo luminoso de $32 \mu \mathrm{mol} \mathrm{m}^{-2} \mathrm{~s}^{-1}$, à temperatura de $27 \pm 2^{\circ} \mathrm{C}$ no Laboratório de Cultura de Células e Tecidos Vegetais do Departamento de Fitotecnia da UFV. A cada 30 dias, as brotações foram repicadas. As plantas que apresentaram problemas no desenvolvimento vegetativo, como nanismo e brotação anormal de ramos foram descartadas. Ao final desse período, as brotações foram transferidas para meio MS isento de citocinina para o seu alongamento e enraizamento.

As plantas foram submetidas a dois ciclos de seleção em meio de cultura MS líquido, suplementado com o filtrado da cultura do fungo. Para a obtenção do filtrado, o isolado foi cultivado em BSA (batata-sacarose-ágar) por duas semanas. Após esse período, um disco de $1 \mathrm{~cm}$ de meio contendo micélios do fungo foi transferido para erlenmeyers com capacidade de $250 \mathrm{~mL}$, contendo $100 \mathrm{~mL}$ de meio Richard. As culturas foram mantidas em agitador orbital a 70rpm por 30 dias. Após esse período, as culturas foram filtradas em papel filtro e o filtrado, centrifugado a $3493 \mathrm{~g}$ por 10 minutos. O sobrenadante contendo material fúngico remanescente foi descartado e o líquido restante foi 
esterilizado com membrana esterilizada apresentando poro de $0,22 \mu \mathrm{m}$, com auxílio de uma bomba de vácuo. Após a esterilização, o filtrado foi mantido a $-5^{\circ} \mathrm{C}$, até o momento da utilização. No primeiro ciclo de seleção, foi utilizado meio MS contendo $40 \%$ de filtrado da cultura fúngica e, no segundo ciclo, $50 \%$ do filtrado. As culturas permaneceram 15 dias em cada meio de seleção, com um intervalo de 30 dias de cultivo em meio MS isento de toxinas fúngicas para o reestabelecimento do crescimento das plantas sobreviventes. Plantas de maracujazeiro amarelo provenientes da germinação em meio de cultura MS foram utilizadas como controle, sendo submetidas aos mesmos ciclos de seleção que as plantas de maracujazeiro amarelo mutantes.

Ao final de cada ciclo de seleção, foi avaliada a porcentagem de plantas sobreviventes. Em todas as etapas dos experimentos in vitro, as culturas foram incubadas em ambiente controlado, à temperatura de $27 \pm 2^{\circ} \mathrm{C}$, com fotoperíodo de 16 horas $\left(32 \mu \mathrm{mol} \mathrm{m} \mathrm{m}^{-2} \mathrm{~s}^{-1}\right)$. O delineamento utilizado foi completamente casualizado, sendo utilizado, no primeiro ciclo de seleção, sete repetições compostas de 100 plantas e, no segundo ciclo, sete repetições de 31 plantas.

As plantas selecionadas foram retiradas dos frascos e as raízes lavadas em água corrente e transferidas para recipientes contendo solução fungicida benomyl $\left(2 \mathrm{~g} \mathrm{~L}^{-1}\right.$ do produto comercial Benlate $\left.{ }^{\circledR}\right)$, cobertos com filme de PVC e mantidos em temperatura ambiente para a aclimatização. Após sete dias, as plantas foram transferidas para sacos plásticos contendo substrato comercial Plantimax ${ }^{\circledR}$ em estufa, com irrigação intermitente por 15 dias.

As plantas selecionadas e aquelas do tratamento controle foram transferidas para vasos contendo areia autoclavada já inoculada com a suspensão do patógeno $\left(4 \times 10^{7}\right.$ conídios $\mathrm{mL}^{-1}$, determinada com auxílio de hemacitômetro tipo Neubauer), sem causar ferimento nas raízes. Foi fornecida às plantas uma solução nutritiva constituída de sais MS (50\%) a cada sete dias e a irrigação foi feita com água autoclavada, quando necessário. O delineamento experimental foi completamente casualizado, sendo utilizadas seis repetições compostas por seis plantas. Foram inoculadas plantas irradiadas e não irradiadas e avaliada a porcentagem de sobrevivência aos 21 dias após a inoculação.

As plantas sobreviventes foram transferidas para o campo, em área com histórico de ocorrência de fusariose, juntamente com plantas não irradiadas, utilizadas como controle, sendo conduzidas em espaldeira com um fio de arame e irrigadas através de sistema de aspersores na área experimental do Setor de Fruticultura da Universidade Federal de Viçosa.

O delineamento experimental foi completamente casualizado, com nove repetições de três plantas cada. As avaliações foram realizadas após 18 meses da implantação das plantas na área, com base na porcentagem de sobrevivência.

Em todos os experimentos, as plantas irradiadas e não irradiadas foram consideradas como os tratamentos e as diferenças detectadas através do teste $\mathrm{F}$ a $5 \%$ de significância. A análise da variância (ANOVA) foi realizada com auxílio do programa SAEG 9.1 (SAEG, 2007).

\section{RESULTADOS E DISCUSSÃO}

As irradiações dos segmentos nodais de $\boldsymbol{P}$. edulis $\boldsymbol{f}$. flavicarpa a 20Gy resultaram na sobrevivência de 1.326 gemas após 30 dias da transferência para meio MS. Esse resultado se aproximou da estimativa de aproximadamente $60 \%$ de sobrevivência observado em ensaios preliminares com a dose de radiações gama de $20 \mathrm{~Gy}$. No entanto, durante os subcultivos em meio MS suplementado com BAP foi observada a morte de aproximadamente $40 \%$ das plantas. Ao final da fase de enraizamento, foram selecionadas 700 plantas com crescimento vegetativo normal, as quais foram usadas nas avaliações em que foi utilizado o filtrado da cultura fúngica como agente seletivo.

Após 15 dias da inoculação em meio de cultura contendo $40 \%$ de filtrado fúngico, observouse que todas as plantas de maracujá-amarelo não irradiadas não sobreviveram. As plantas provenientes dos tratamentos com radiação gama apresentaram maior tolerância ao filtrado, ficando a porcentagem de sobrevivência destas em 31\% (Tabela 1). Em FLORES et al. (2012), foi registrada a produção de raízes de plantas de maracujazeiro amarelo em meio de cultura suplementado com $40 \%$ de filtrado e, portanto, a sobrevivência de plantas, apesar de os autores não terem avaliado este último parâmetro. As observações dos autores podem ter sido resultado da adaptação epigenética das células vegetais aos agentes seletivos. Segundo RAI et al. (2011), esse fenômeno é comum na seleção in vitro, quando o material vegetal passa por vários ciclos de seleção. Em FLORES et al. (2012), as plantas foram previamente selecionadas com o uso de ácido fusárico e posteriormente submetidas a ciclos de seleção em meio contendo filtrado fúngico em concentrações crescentes (de 10\%, 20\%, 30\% e $40 \%$ ), ao contrário do presente trabalho, em que foram testadas apenas as concentrações de 40 e 50\%. 
Salienta-se ainda que alguns autores afirmam que o ácido fusárico, em baixas concentrações, pode induzir a resistência de plantas a fungos do gênero Fusarium (CURIR et al., 2000; SAMADI \& BEHBOODI, 2006; BOUIZGARNE et al., 2006), podendo ser esta, outra possível causa da sobrevivência das plantas de maracujazeiro amarelo em $40 \%$ de filtrado, conforme observado por FLORES et al. (2012). Tendo em vista a morte de $100 \%$ das plantas não irradiadas quando tratadas com $40 \%$ da cultura fúngica, a reação dessas plantas não foi avaliada com a concentração de $50 \%$ do filtrado.

Após 15 dias do segundo ciclo de seleção, no qual as plantas foram mantidas em meio de cultura contendo $50 \%$ do filtrado, foi observada $17,05 \%$ de sobrevivência (Tabela 1). Observou-se a intensa formação de raízes e alto vigor vegetativo das plantas sobreviventes (Figura 1).

Após a aclimatização das plantas selecionadas in vitro e inoculação com a suspensão do patógeno, a porcentagem de sobrevivência das plantas irradiadas foi de $72,97 \%$ e das plantas não irradiadas foi $70,11 \%$, não resultando em diferença significativa (Tabela 1). Esse resultado reflete a dificuldade encontrada para determinação de metodologia de inoculação artificial in vivo de plantas de maracujazeiro amarelo com o fungo $\boldsymbol{F}$. oxysporum $f$. sp passiflorae. Atualmente, a avaliação das plantas a campo é a metodologia mais utilizada e aceita para seleção de plantas de maracujazeiro resistentes a fusariose (LARANJEIRA et al., 2005), apesar de outros patógenos ou até mesmo outros patótipos do fungo presentes no solo poder dificultar as inferências sobre a resistência dos acessos através desta metodologia (SILVA et al., 2011). O desenvolvimento de uma metodologia de diagnose precoce e mais precisa para verificar a reação de plantas de maracujazeiro amarelo a fusariose in vivo tem sido um desafio para a pesquisa. FLORES et al. (2012) incubaram plantas de maracujazeiro em areia autoclavada, contendo suspensão do patógeno de $\boldsymbol{F}$. oxysporum $\boldsymbol{f}$. sp. passiflorae em câmara de crescimento com temperatura constante de $27 \pm 2^{\circ} \mathrm{C}$ e fotoperíodo de 16 horas de luz. Após sete dias da inoculação, não foi verificada diferença significativa na taxa de sobrevivência das plantas previamente identificadas in vitro como resistentes e suscetíveis através do uso do filtrado fúngico. SILVA et al. (2011) avaliaram a eficiência de métodos de inoculação artificial de plantas de maracujazeiro amarelo com F. oxysporum $\boldsymbol{f}$. sp. passiflorae e concluíram que a imersão das raízes na suspensão do inóculo em câmara de crescimento a $25 \pm 3^{\circ} \mathrm{C}$ foi o método mais eficiente, baseando-se na menor taxa de sobrevivência observada $(37,5 \%)$ após 20 dias da inoculação. No entanto, estes autores não avaliaram variedades resistentes para confirmar a eficiência do método na identificação de genótipos resistentes e suscetíveis.

Após um ano e meio da transferência das plantas para área com histórico da doença, 77,78\% (21 plantas) das plantas provenientes de material irradiado sobreviveram (Tabela 1). Nenhuma das plantas do tratamento testemunha sobreviveu após este período, apresentando sintomas típicos da doença como amarelecimento das folhas, murchamento e seca. Resultados semelhantes foram observados por SHARMA et al. (2010), os quais observaram que, das 486 progênies mutantes de ervilha, apenas 25 apresentaram resistência à murcha causada por $\boldsymbol{F}$. oxysporum $\boldsymbol{f}$. sp. Pisi, quando transferidos para área com histórico da doença, e todas as plantas controle apresentaram os sintomas.

Das plantas de maracujazeiro amarelo sobreviventes, apenas $38,11 \%$ apresentaram crescimento vegetativo normal e produção de frutos, o que correspondeu a oito plantas. A mutação é um evento aleatório e, apesar de ser empregada na obtenção de variantes de interesse agronômico, gera um grande número de plantas com aberrações, como a inibição do crescimento, alteração do metabolismo,

Tabela 1 - Sobrevivência de plantas de maracujazeiro amarelo inoculadas com Fusarium oxysporum $\boldsymbol{f}$. sp. passiflorae, tratadas ou não com raios gama.

\begin{tabular}{lcc}
\hline Método de seleção & Plantas irradiadas & Plantas não irradiadas \\
\hline Meio seletivo com $40 \%$ filtrado da cultura fúngica & $31,00 \pm 9,03$ & 0 \\
Meio seletivo com 50\% filtrado da cultura fúngica & $17,05 \pm 3,49$ & - \\
Com suspensão de esporos, em estufa & $72,97 \pm 11,12 \mathrm{a}$ & $70,11 \pm 15,12 \mathrm{a}$ \\
Em área com histórico da doença & $77,78 \pm 19,49$ & 0 \\
\hline
\end{tabular}

Números seguidos da mesma letra não diferem entre si pelo teste F a 5\% de probabilidade de erro. (-) dados não avaliados. 




anomalias morfológicas e problemas na fertilidade (PIRI et al., 2011). Por isso, é necessário irradiar um número grande de material vegetal para se obter um número adequado de plantas com as características de interesse e sem anomalias que impeçam sua multiplicação ou comprometam sua fertilidade.

Em vários trabalhos, tem sido demonstrada a eficiência do uso de toxinas como agentes seletivos de plantas resistentes a doenças (SHARMA et al., 2010; KANTOGLU et al., 2010; FLORES et al., 2012). Através do uso do filtrado da cultura de $\boldsymbol{F}$. oxysporum f. sp. Passiflorae, FLORES et al. (2012) puderam diferenciar plantas sensíveis e insensíveis ao fungo e os resultados foram confirmados in vivo. No presente trabalho, a técnica foi associada à indução de mutações como maneira de aumentar a frequência de plantas resistentes ao fungo. Segundo MAHLANZA et al. (2013), é possível que a indução de mutações que conferem resistência ao Fusarium atue contra compostos produzidos pelo fungo e que inibem o desenvolvimento da raiz, sendo possível observar a retomada do crescimento radicular nas plantas tolerantes desafiadas pelo patógeno. Adicionalmente, no presente trabalho, foram avaliadas as reações das plantas em área com histórico da doença e, de acordo com os resultados a eficiência do uso de toxinas como agentes seletivos de plantas resistentes a fusariose associada a mutações induzidas, foi confirmada através dos testes a campo.

\section{CONCLUSÃO}

De acordo com os resultados, o tratamento com raios gama aumentou a sobrevivência das plantas de maracujazeiro quando inoculadas com o filtrado da cultura de $F$. oxysporum $f$. sp. passiflorae e em área com histórico da doença. No entanto, não foram observadas diferenças na sobrevivência das plantas irradiadas e não irradiadas quando estas foram inoculadas com o fungo em casa de vegetação.

\section{AGRADECIMENTOS}

Ao Dr. Francisco Laranjeira da Embrapa Mandioca e Fruticultura, por ceder o isolado de F. oxysporum $\boldsymbol{f}$ sp. passiflorae utilizado neste trabalho. À Coordenação de Aperfeiçoamento de Pessoal de Nível Superior (CAPES) e ao Conselho Nacional de Desenvolvimento Científico e Tecnológico (CNPQ), pelo apoio financeiro.

\section{REFERÊNCIAS}

BOUIZGARNE, B. et al. A putative role for fusaric acid in biocontrol of the parasitic angiosperm Orobanche ramosa. 
Molecular Plant-Microbe Interactions, v.19, n.5, p.550-556, 2006. Disponível em: <http://dx.doi.org/10.1094/MPMI -190550>. Acesso em: 15 abr. 2013. doi: 10.1094/MPMI -19-0550.

CAVICHIOLI, J.C. et al. Desenvolvimento e produtividade do maracujazeiro-amarelo enxertado em três porta-enxertos. Revista Brasileira de Fruticultura, v.33, n.2, p.567-574, 2011. Disponível em: $<$ http://dx.doi.org/10.1590/S0100-29452011005000056>. Acesso em: 06 jan. 2012. doi: 10.1590/S0100-29452011005000056.

CHEN, Y.F. et al. Fusarium wilt-resistant lines of Brazil banana (Musa spp.,AAA) obtained by EMS-induced mutation in a micro-crosssection cultural system. Plant Pathology,v.62, p.112-119, 2013. Disponível em: <http://dx.doi.org/10.1111 /j.1365-3059.2012.02620.x>. Acesso em: 12 jan. 2013. doi: 10.1111/j.1365-3059.2012.02620.x

CURIR, P. et al. Fusaric acid production by Fusarium oxysporum in the lily basal rot disease. European Journal of Plant Pathology, v.106, p.849-856, 2000. Disponível em: <http://dx.doi. org/10.1023/A:1008739708931>. Acesso em: 15 jan. 2013. doi: 10.1023/A:1008739708931

FLORES, P.F. et al. In vitro selection of yellow passion fruit genotypes for resistance to Fusarium vascular wilt. Plant Cell, Tissue and Organ Culture, v.108, n.1, p.37-45, 2012. Disponível em: <http://dx.doi.org/10.1007/s11240-011-0009-5>. Acesso em: 05 jul. 2012. doi: 10.1007/s11240-011-0009-5.

JAIN S. M. In vitro mutagenesis in banana (Musa spp.) improvement. Acta Horticulturae, v.879, p.605-614, 2010 Disponível em: <www.banana2008.com/cms/details/acta/879_67. pdf>. Acesso em: 09 jan. 2013.

KANTOGLU, Y. et al. Improving tolerance to Fusarium oxysporum f. sp. melonis in melon using tissue culture and mutation techniques. In: . Mass screening techniques for selecting crops resistant to disease. Vienna: International Atomic Energy Agency, 2010. Cap.14, p.235-244.

LARANJEIRA, F.F. et al. Progresso da fusariose do maracujá em porta-enxertos do gênero Passiflora. In: CONGRESSO BRASILEIRO DE FITOPATOLOGIA, 38., 2005, Brasília, DF. Fitopatologia Brasileira - Suplemento. Local: Brasília - DF, Sociedade Brasileira de Fitopatologia, 2005. V.30, p.146. Disponível em: <http://www.sbfito.com.br/tpp/Suplemento 2005 Brasilia.pdf>. Acesso em: 09 out. 2012.

MAHLANZA, T. et al. In vitro generation of somaclonal variant plants of sugarcane for tolerance to Fusarium sacchari. Plant Cell Report, v.32, n.2, p.249-262, 2013. Disponível em: <http:// dx.doi.org/10.1007/s00299-012-1359-0>. Acesso em: $12 \mathrm{fev}$. 2013. doi: 10.1007/s00299-012-1359-0.

MELETTI, L.M.M et al. Melhoramento genético do maracujá: passado e futuro. In: FALEIRO, F.G. et al. (Org.). Maracujá: germoplasma e melhoramento genético. Planaltina: EMBRAPA CERRADOS, 2005. V.1, p.55-78

MELETTI, L.M.M. Avanços na cultura do maracujá no Brasil. Revista Brasileira de Fruticultura, v.33, n. esp, p.83-91, 2011. Disponível em: $<\mathrm{http} / /$ dx.doi.org/10.1590/S0100-29452011000500012>. Acesso em: 01 nov. 2012. doi: 10.1590/S0100-29452011000500012.
MODGIL M. et al. Identifying somaclonal variants of the apple rootstock Malling 7 resistant to white root rot. Scientia Horticulturae, v.137, n.1, p.148-155, 2012. Disponível em: $<$ http://dx.doi.org/10.1016/j.bbr.2011.03.031>. Acesso em: 12 mar. 2013. doi: 10.1016/j.bbr.2011.03.031

MOHAN JAIN, S. A review of induction of mutation in fruit of tropical and subtropical regions. Acta Horticulturae, v.575, p.295-302, 2002. ISBN: 978-90-66058-85-9.

MURASHIGE, T.; SKOOG, F. A revised medium for a rapid growth and bioassays with tobacco tissues cultures. Physiologia Plantarum, v.15, n.3, p.473-479, 1962. Disponível em: <http:// dx.doi.org/10.1111/j.1399-3054.1962.tb08052.x/pdf>. Acesso em: 05 jul. 2012. doi: 10.1111/j.1399-3054.1962.tb08052.x.

NOGUEIRA FILHO, G.C. et al. Produção de mudas de maracujazeiro-amarelo por enxertia hipocotiledonar sobre sete espécies de passifloras. Revista Brasiseira de Fruticultura, v.33, n.1, p.237-245, 2011. Disponível em: <http://dx.doi.org/10.1590/ S0100-29452011005000027>. Acesso em: 01 jan. 2011. doi: 10.1590/S0100-29452011005000027.

PIRI et al. The use of gamma irradiation in agriculture. African Journal of Microbiology Research, v.5, n.32, p.5806-5811, 2011. Disponível em: $<$ http://dx.doi.org/10.5897/AJMR11.949>. Acesso em: 01 jan. 2011. doi: 10.5897/AJMR11.949.

RAI, M.K. et al. Developing stress tolerant plants through in vitro selection - An overview of the recent progress. Environmental and Experimental Botany, v.71, n.1, p.89-98, 2011. Disponível em: <http://dx.doi.org/10.1016/j.bbr.2011.03.031>. Acesso em: 01 jan. 2011. doi: 10.1016/j.bbr.2011.03.031.

SAEG. Sistema para análise estatística e genética - Versão 9.1. Viçosa, MG: Fundação Arthur Bernardes, 2007. 59p. (Manual do usuário).

SAMADI, L.; BEHBOODI, B.S. Fusaric acid induces apoptosis in saffron root-tip cells: roles of caspase-like activity, cytocrome c, and $\mathrm{H}_{2} \mathrm{O}_{2}$. Planta, v.225, n.1, p.223-234, 2006. Disponível em: $<$ http://dx.doi.org/10.1007/s00425-006-0345-6>. Acesso em: 01 jan. 2013. doi: 10.1007/s00425-006-0345-6.

SHARMA, A. et al. Induction of Fusarium wilt (Fusarium oxysporum f. sp. pisi) resistance in garden pea using induced mutagenesis and in vitro selection techniques. Euphytica, v.173, n.3, p.345-356, 2010. Disponível em: <http://dx.doi.org/10.1007/ s10681-009-0099-x.>. Acesso em: 03 jan. 2013. doi: 10.1007/ s10681-009-0099-x

SILVA, A. dos S. et al. Seleção de metodologias para inoculação da fusariose do maracujazeiro causada por Fusarium oxysporum $f$. sp. passiflorae. Cruz das Almas: Embrapa Mandioca e Fruticultura, 2011. 20p. (Boletim de Pesquisa e Desenvolvimento, 51)

SNYMAN, S.J. et al. Applications of in vitro culture systems for commercial sugarcane production and improvement. In Vitro Cellular and Developmental Biology - Plant, v.47, n.2, p.234249, 2011. Disponível em: <http://dx.doi.org/10.1007/s11627011-9354-7>. Acesso em: 01 jan. 2012. doi: 10.1007/s11627-0119354-7. 